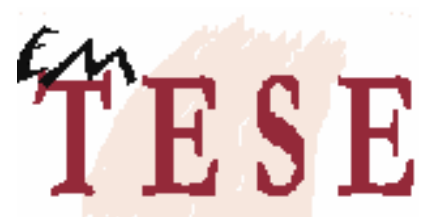

Revista Eletrônica dos Pós-Graduandos em Sociologia Política da UFSC

Vol. 4 n. 2 (2), janeiro-julho/2008

ISSN 1806-5023

\title{
Nanotecnologia na imprensa: análise de conteúdo do jornal Folha de São Paulo
}

\author{
Tade-Ane de Amorim ${ }^{1}$
}

Resumo:

O artigo apresenta uma análise de conteúdo sobre como a nanotecnologia vem sendo abordada no jornal de maior circulação nacional, a Folha de São Paulo. Como a nanotecnologia é um assunto relativamente recente, conseguimos analisar todas as notícias que trouxeram a nanotecnologia como temática, desde a primeira vez em que a nanotecnologia foi noticiada pelo jornal até o março de 2007, um retrospecto de dez anos. Observa-se mudanças significativas no modo como a temática foi apresentada no jornal nesse período. No início as promessas dessa nova tecnologia eram apresentadas como "revolucionárias", ou seja, como potencialidades de melhorar a vários aspectos da vida humana. Depois o jornal passou a apresentar algumas controvérsias sobre os riscos da nanotecnologia e as notícias passaram a apresentar inovações mais pontuais do tema.

Palavras chaves: Nanotecnologia, Análise de Conteúdo, Folha de São Paulo.

Abstract:

This study was elaborated with the intention of showing a content analysis in how Nanotechnology has been informed by the national newspapers with the biggest circulated number of editions, Folha de São Paulo. As Nanotechnology is a relatively recent issue, we had the conditions to analyze all the news which brought Nanotechnology as a thematic since its first time, when Nanotechnology was made headline by the newspaper until March 2007, which corresponds to a ten years period of time. We had the conditions to be aware about significant changes in the way how the thematic was shown by the Journal in the period of time. In a very beginning, the promises of this new technology were shown as "revolutionaries", means, as potentialities ways to make better the many aspects of the human life. After that, the Journal started to show some controversies about the risks of Nanotechnology and the headlines turned in another way, showing more precise innovations of Nanotechnology.

Keywords: Nanotechnology, Content Analysis, Folha de São Paulo.

\footnotetext{
${ }^{1}$ Doutoranda do Programa de Pós-Graduação em Sociologia Política - UFSC (bolsista CAPES); Mestre em Sociologia Política e Bacharel em Ciências Sociais ambos pela UFSC. Email: tade-ane@hotmail.com
} 


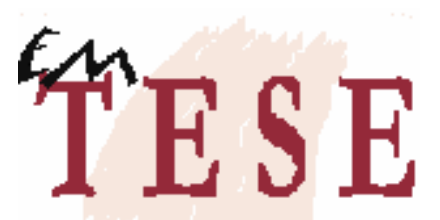

Revista Eletrônica dos Pós-Graduandos em Sociologia Política da UFSC

Vol. 4 n. 2 (2), janeiro-julho/2008

ISSN 1806-5023

\section{Conhecer o desconhecido e desconhecer o conhecido}

Vivemos num mundo que nos é desconhecido, o nosso desafio, enquanto pesquisadores é torná-lo conhecido; a relação do conhecimento se faz com o desconhecido. Mas como tornar o desconhecido, nosso conhecido? O conhecimento é uma construção, uma formulação e é distinto do real, mas nosso objetivo é apreender se não o real, ao menos um fragmento desse real. Entendemos a realidade como uma aproximação. As teorias científicas ajudam a construir a realidade, que passam a fazer parte de nossa realidade a partir de teorias e conceitos. Como nos lembra Bachelard - "As paralelas existem depois, não antes do postulado de Euclides." (1988, p.318, grifos do autor). Concordamos com Cardoso, quando ela afirma que a relação com o conhecimento é sempre uma aproximação, tal como é exposto abaixo:

“ 'O objeto' é sempre inatingível. Cada teoria o formula, como seu objeto, segundo seus pressupostos, segundo a sua postura diante dele. Neste sentido, o objeto do conhecimento é uma "representação" feita pela teoria, tentando reproduzir o real, numa visão sempre mais aprofundada, sempre mais simples e mais geral, buscando nexos e relações, interpretando as aparências, tratando-as como sinais ou indícios parciais a que se confere significado ao encontrar para eles um lugar nas construções mais amplas, teóricas.” (Cardoso, 1978, p.26)

Se a tarefa da ciência é fazer aproximações com o real, o jornalismo, sobretudo o de divulgação científica ${ }^{2}$ busca traduzir a discussão científica para o público. Realizando uma aproximação com o conhecimento. Certamente essa "tradução" não é neutra, mas mostra a percepção de ciência dos jornalistas que o escreveram. Nesse artigo, discutiremos como a Nanotecnologia vem sendo apresentada/traduzida aos leitores do jornal de maior circulação nacional, a Folha de São Paulo. Para os cientistas, é importante o reconhecimento do público, é interessante que o público perceba que os cientistas estão desenvolvendo tecnologias que ajudarão a solucionar problemas vivenciados no cotidiano. Pois é a partir de demandas dispersas do público, dos setores empresariais e da comunidade científica que são abertos os fundos de investigação científica e definidas prioridades no investimento estatal em pesquisa. Como o

2 No editorial do número inaugural da Ciência Hoje, os editores definiram Divulgação Científica como “(...) a tentativa, seja por cientistas, seja por jornalista, de fornecer à sociedade uma descrição inteligível da atividade criadora dos cientistas e de esclarecer questões técnicas e científicas de interesse geral." 


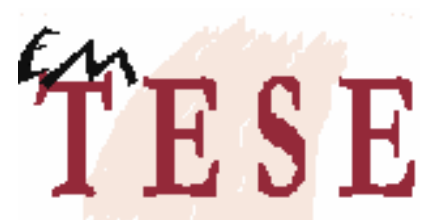

Revista Eletrônica dos Pós-Graduandos em Sociologia Política da UFSC

Vol. 4 n. 2 (2), janeiro-julho/2008

ISSN 1806-5023

objetivo é analisar artigos jornalísticos, acreditamos que a metodologia da análise de conteúdo é a mais adequado, pois nos permitirá uma leitura quantitativa e qualitativa das matérias. Ao mesmo tempo em que nos possibilitará ir além do aparente, do evidente e com isso aprofundarmos a análise.

\section{Análise de conteúdo, o que é isso?}

A análise de conteúdo, não é um método recente, mas remonta da Idade Média que no princípio buscou interpretar textos bíblicos. Como nos explica CHIZOTTI:

surgiu ainda na Idade Média, com os estudos da Escolástica medieval, aplicados à exegese bíblica. Isto é, os primeiros estudos de interpretação do sentido dos textos bíblicos. Posteriormente, passou a ser utilizada também pelos hermeneutas, no campo da literatura, com a hermenêutica literária, a qual tinha como objetivo realizar interpretações de textos literários. Mais tarde, passou a ser aplicada também à interpretação de sonhos, com o advento dos estudos psicanalíticos. (CHIZOTTI, 1991, p. 98)

Nas ciências sociais, o trabalho de Thomas e Znaiecki feito entre 1908 e 1918, sobre emigrantes poloneses na Europa e Estado Unidos, pode ser considerado como pioneiro na análise de conteúdo. Os pesquisadores usaram materiais diversificados, tais como cartas, diário pessoais, relatórios oficiais e artigos de jornal. Ainda que as fontes tenham sido diversas, o resultado é apontado como uma análise de conteúdo ainda bastante elementar (Bardin, 1979). Foi no jornalismo, sobretudo na escola de jornalismo da Universidade de Colúmbia, que se desenvolveu vários estudos, na maior parte deles, quantitativos, de jornais. Iniciam-se nessa fase estudos sobre tamanho e superfície ocupada pelas matérias, tamanho dos títulos, localização na página. A análise de conteúdo foi recorrentemente usada nesse momento.

Durante a segunda guerra mundial, e nos anos seguintes, a ciência política passou a ocupar lugar de destaque no desenvolvimento da análise de conteúdo. O governo NorteAmericano solicitava a diferentes pesquisadores, análises de conteúdo para "desmascarar" jornais e periódicos com conteúdos considerados subversivos (Bardin, 1979). Vários cientistas se debruçaram sobre jornais na busca de artigos que trouxessem defesas nazistas.

Outra vertente de análise de conteúdo foram os trabalhos sobre análise da personalidade. Repercutiu o caso da análise das "Cartas de Jenny", nesse estudo, três 


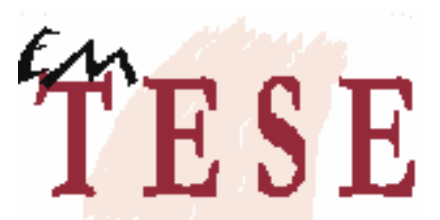

Revista Eletrônica dos Pós-Graduandos em Sociologia Política da UFSC

Vol. 4 n. 2 (2), janeiro-julho/2008

ISSN 1806-5023

pesquisadores, em diferentes momentos, analisaram 167 cartas escritas por uma pessoa com neurose (Bardin, 1979).

Com maior número de pesquisadores utilizando a análise de conteúdo, ampliou-se a preocupação metodológica e epistemológica sobre a temática. As tentativas de definições começam a surgir. Como a de Berelson, que afirma que:

“A análise de conteúdo é uma técnica de investigação que tem por finalidade a descrição objectiva, sistemática e quantitativa do conteúdo manifesto da comunicação" (Berelson, 1952, apud Bardin, 1979, p.16)

Nos trabalhos posteriores essa perspectiva foi sendo questionada e ampliada, bem como as aplicações da técnica. Historiadores, psiquiatras, psicanalistas e lingüistas passaram a usar a técnica e a discutir metodologia e os pressupostos epistemológicos. A discussão tratava, sobretudo acerca das abordagens qualitativa e quantitativa. Nas análises quantitativas a preocupação dos investigadores versava sobre a freqüência de determinada palavra, conceito ou expressão; já na análise qualitativa eram consideradas a presença ou ausência de conteúdos e/ou um conjunto de características em determinado texto. (Bardin, 1979).

A partir da década de 60 têm-se a presença de análise de conteúdo transitando por vertentes qualitativas e quantitativas. Favoreceu esse processo o uso do computador que permitiu ampliar a quantidade de dados, que manualmente seriam impossíveis de ser assimilados e analisados.

A análise de conteúdo pode ser utilizada para diversos fins, como já apontamos antes, desde análise de textos históricos até análise de propagandas. Em relação as possibilidades de seu uso, Pereira, 1998 p. 94 esclarece:

Dois objetivos estão presentes ao recorrermos à análise de conteúdo: ultrapassar a incerteza e enriquecer a leitura. No primeiro caso, a análise de conteúdo ajuda a demonstrar que a leitura particular do observador é válida e generalizável. O segunda aspecto diz respeito a descobrir conteúdos e estruturas das mensagens e esclarecer elementos de significações de mecanismos não imediatamente perceptíveis.

Assim, a análise de conteúdo nos permite distanciarmos de uma sociologia ingênua, ou a crença na transparência dos dados. Como nos lembra Bachelard:

(...) os traços aparentes não são sempre os traços mais característicos; é preciso resistir a um positivismo de primeiro exame. Se se falha nessa 


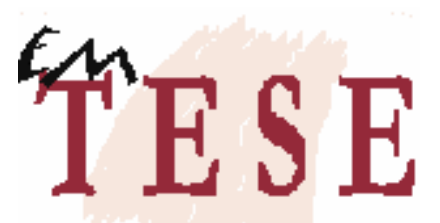

Revista Eletrônica dos Pós-Graduandos em Sociologia Política da UFSC

Vol. 4 n. 2 (2), janeiro-julho/2008

ISSN 1806-5023

prudência, corre-se o risco de tomar uma degenerescência por uma essência." (1988, p.326)

\section{A nanotecnologia na Folha de São Paulo}

Fizemos uma busca de todas as matérias que apareciam a palavra Nanotecnologia no jornal Folha de São Paulo. A escolha por esse jornal se deve ao fato de ser o jornal de maior circulação nacional, com distribuição de 360.994 exemplares aos domingos e 287.842 exemplares nos demais dias ${ }^{3}$. Além disso, o jornal tem uma coluna diária sobre ciência, o que o levou a ter publicado várias matérias sobre o assunto que pretendemos analisar.

Sendo este um assunto bastante recente ${ }^{4}$, pudemos analisar desde a primeira vez que a Folha de São Paulo utilizou o termo nanotecnologia, no ano de 1996 até o dia 10 de fevereiro de 2007, data de finalização da coleta de dados. O recurso de busca eletrônica facilitou o processo de seleção, pois no jornal há um mecanismo de busca ${ }^{5}$, que possibilita rápido acesso a todos as matérias. Assim digitei a palavra "Nanotecnologia" e apareceram 234 ocorrências. O interessante de usarmos o recurso de busca eletrônica é a precisão com que a busca é feita, como todas as ocorrências, da palavra procurada, são elencadas, é possível ampliarmos o espaço temporal em que realizamos a análise. Mesmo com esse recurso, cabe ao pesquisador o processo fatigoso de separar o "joio do trigo", ou seja, separar as notícias sobre nanotecnologia das notícias em que apenas apreciam esse termo, entretanto discorriam sobre outros assuntos; notícias no formato de pequenas notas (com apenas um parágrafo) e ainda artigos da seção "Opinião". Assim, iniciamos a composição da amostra com a exclusão de 23 pequenas notas; 20 chamadas para a notícia do dia seguinte, que apareceram no mecanismo de busca apenas por conter no título a palavra nanotecnologia e 3 artigos da seção "Opinião". Depois realizamos a leitura de todas as notícias e excluímos as 129 notícias que usavam o termo nanotecnologia, mas não discorriam sobre o assunto.

A amostra final foi composta por 61 textos. Depois dessa seleção, seguindo as orientações metodológicas de Bardin (1979) realizamos uma "leitura flutuante", no intuito de obtenção das primeiras impressões. Após essa leitura optamos por analisar as

3 Dados obtidos no site do jornal (www.folha.com.br) extraído no dia 20 de fevereiro de 2007.

4 Foi o físico norte-americano Feynman, no ano de 1959, o primeiro cientista a propor a .

5 Desde 1994 todos os textos da Folha de São Paulo estão digitalizados e disponíveis a seus assinantes ou assinantes do portal UOL. 


\section{留ESE}

Revista Eletrônica dos Pós-Graduandos em Sociologia Política da UFSC

Vol. 4 n. 2 (2), janeiro-julho/2008

ISSN 1806-5023

notícias sobre nanotecnologia em todas as seções do jornal. Inicialmente, havíamos pensado que a análise ficaria restrita a seção "Ciência", mas a mudança se deu

principalmente ao percebermos que houve uma significativa ocorrência da nanotecnologia na seção "Negócios" no ano de 2006. Tal como exposto no gráfico e na tabela:

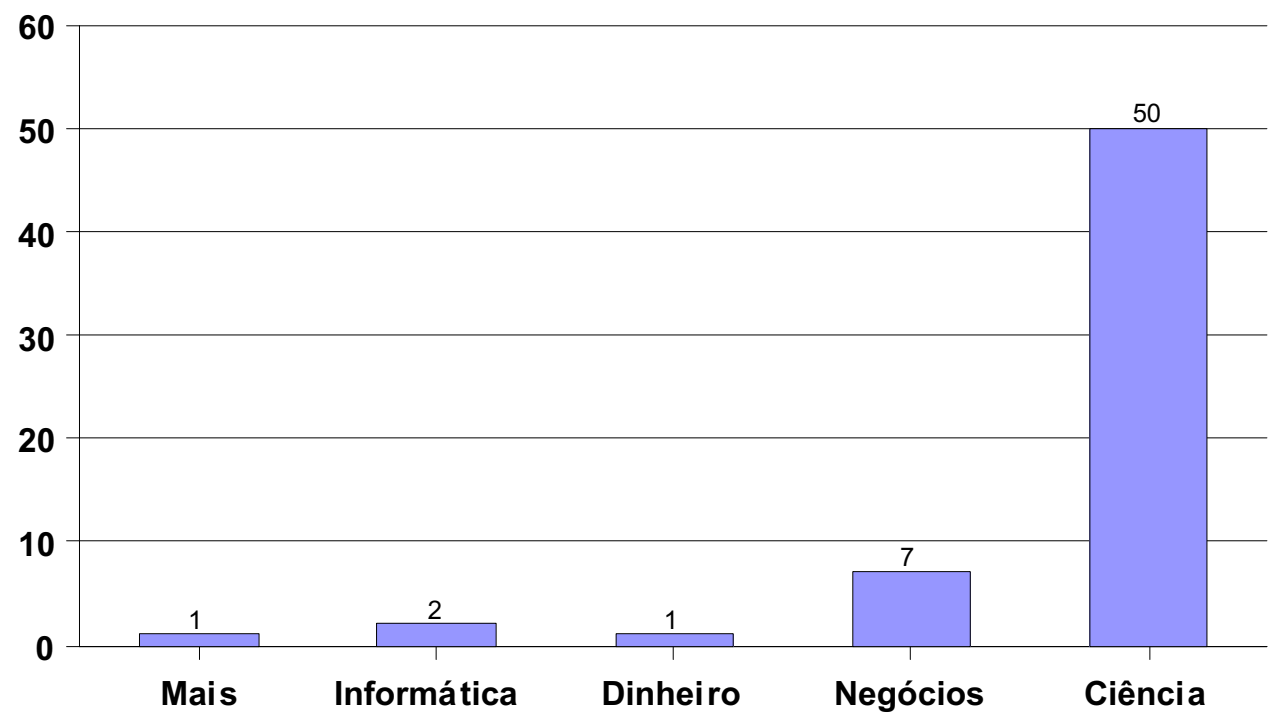

Notícias sobre Nanotecnologia por seções do jornal

de acordo com o esperado foi na seção "Ciência" que essa temática foi mais recorrente,atentamos para o fato de que no nos últimos dois anos houve maior incidência de notícias nas seções "Dinheiro" e "Negócio". A distribuição de notícias sobre nanotecnologia, por ano e seção, no jornal Folha de São Paulo, se deu da seguinte forma: 


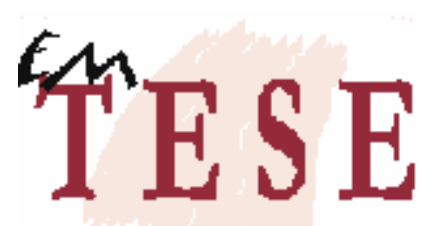

Revista Eletrônica dos Pós-Graduandos em Sociologia Política da UFSC

Vol. 4 n. 2 (2), janeiro-julho/2008

ISSN 1806-5023

Distribuição das notícias sobre nanotecnologia por seção e ano

\begin{tabular}{|l|c|c|c|c|c|c|c|}
\hline Ano Seção & Ciência & Negócios & Dinheiro & Informática & Mais & Especial & Total \\
\hline 1997 & 02 & - & - & - & - & - & 02 \\
\hline 1999 & 02 & - & - & - & - & - & 02 \\
\hline 2000 & 02 & - & - & 01 & - & - & 03 \\
\hline 2001 & 03 & - & - & 01 & - & - & 04 \\
\hline 2002 & 04 & - & - & - & - & - & 04 \\
\hline 2003 & 07 & - & - & - & - & - & 07 \\
\hline 2004 & 06 & - & - & - & 01 & - & 07 \\
\hline 2005 & 07 & - & - & - & - & - & 07 \\
\hline 2006 & 08 & - & - & - & - & 01 & 09 \\
\hline 2007 & 06 & 07 & 01 & 01 & - & - & 15 \\
\hline Total & 01 & - & - & - & - & - & 01 \\
\hline
\end{tabular}

É interessante percebermos que até o ano de 2005 as notícias estavam concentradas na seção "Ciência" e no ano de 2006 houve predominância nas seções "Negócios” (07) e 1 notícia na seção "Dinheiro". Até agora apresentamos os resultados da análise de conteúdo quantitativa. A seguir, apresentaremos os resultados da análise de conteúdo qualitativa.

Para realizarmos a análise de conteúdo de forma qualitativa, nossa primeira tarefa foi desenvolver categorias de análise. A primeira dessas categorias, foi a separação entre notícias que apresentam os possíveis efeitos positivos da nanotecnologia e aquelas que apresentam os possíveis efeitos negativos. Recorrendo ao texto bem conhecido de Umberto Eco, podemos dizer que dividimos as notícias entre 'Integrados' e 'Apocalípticos ${ }^{6}$. De fato, os efeitos da nanotecnologia estão no campo das incertezas, primeiramente por se tratar de uma tecnologia nova e, em que ainda não há definições governamentais e normatizações científicas sobre as pesquisas. Com isso, o espaço para reações extremadas, tanto de ataque como de defesa ficam mais

6 Umberto Eco propunha a divisão nas categorias Integrados e Apocalípticos frente as reações face à cultura de massas e indústrias culturais: de um lado, o primeiro grupo, que entendia a massificação da produção e consumo como uma a perda da essência da criação artística, e, do outro, os que pensavam estar diante de grandes avanços civilizatórios perante uma democratização da cultura. 


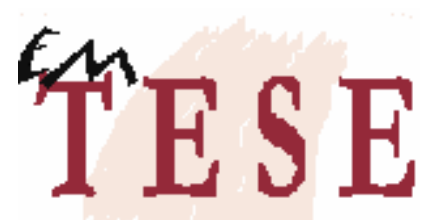

Revista Eletrônica dos Pós-Graduandos em Sociologia Política da UFSC

Vol. 4 n. 2 (2), janeiro-julho/2008

ISSN 1806-5023

evidenciados. Outra categoria de análise, foi o maneira como o conceito de nanotecnologia foi explicado aos leitores. Percebemos que a nanotecnologia foi explicada de maneira diferente, por vezes como minúsculas máquinas (nanomáquinas ou nanorrobôs) e por vezes como uma escala de medida.

\section{Chips menores e vidas maiores, a esperança na nano}

Dos 63 artigos analisados é notório que a maior parte deles foca na apresentação dos possíveis benefícios da nanotecnologia, sobretudo, na melhora da saúde da população e na possibilidade de desenvolvimento de computadores menores, melhores e mais velozes. O primeiro artigo $^{7}$ em que a temática da nanotecnologia apareceu, percebemos claramente que é depositado uma esperança nos benefícios futuros que possivelmente seriam trazidos com o avanço da nanotecnologia. O texto explica o que é nanotecnologia e apresenta as grandes possibilidades que essa nova tecnologia poderia representar para a espécie humana.

Os pesquisadores dessa nova área pretendem desenvolver, por exemplo, robôs microscópicos, capazes de penetrar no corpo humano para combater agentes infecciosos e reparar artérias danificadas. As pessoas poderão viver por mais tempo se esses equipamentos, milhares de vezes menores que a espessura de um fio de cabelo, forem capazes de reparar qualquer parte do organismo, deixando-o em perfeito estado. Chips de computadores, muito mais potentes que os atuais, deverão ser tão pequenos que só poderão ser medidos em nanômetros -unidade de medida que corresponde à bilionésima parte do metro. Eles deverão armazenar grandes quantidades de informação nesse espaço e deverão ser mais rápidos, com os dados a percorrer

7 A primeira vez que a palavra Nanotecnologia apareceu na Folha de São Paulo a reportagem apresentava um jogo de computador. “'Blam - Machinehead' é uma batalha que acontece em 2020, quando a nanotecnologia (téenica que utiliza máquinas em miniaturas para produção de qualquer coisa) é dominante no mundo. Um maluco se apropria dessa tecnologia e começa a fabricar tudo que imagina." (Folha de São Paulo, 19 de fevereiro de 1997, grifos nossos). Mesmo não sendo fonte de nossa análise, por não abordar diretamente a temática que aqui nos interessa, é relevante marcarmos que a primeira vez que a Nanotecnologia é escrita é usado como uma ameaça futura. Outra questão interessante é percebermos qual a explicação é dada para nanotecnologia. 


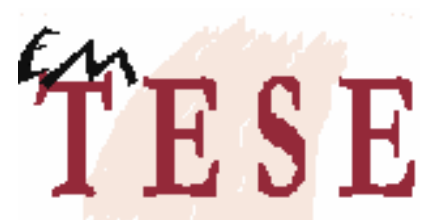

Revista Eletrônica dos Pós-Graduandos em Sociologia Política da UFSC

Vol. 4 n. 2 (2), janeiro-julho/2008

ISSN 1806-5023

distâncias microscópicas. (Folha de São Paulo 19 de 10 de 1997, grifos nossos)

Além da esperança em vivermos mais e armazenarmos mais dados, a primeira matéria sobre nanotecnologia mostra esperanças de no futuro conseguirmos baratearmos diversos artefatos:

Diversos produtos poderão ser fabricados por equipamentos do tamanho de um forno de microondas. E tudo poderá custar muito pouco, porque a matéria-prima existe em abundância na natureza: os átomos. (Folha de São Paulo 19 de outubro de 1997, grifos nossos)

Essa perspectiva de otimismo em relação a essa tecnologia marca o início das publicações. Apesar de apresentar grandes potencialidades, as matérias ainda são pouco freqüentes, a segunda notícia foi apresentada somente sete meses depois. Dessa vez, a reportagem apresentava um resultado concreto da nanotecnologia, a saber, o desenvolvimento de um fio de prata em escala nanométrica:

"Cientistas israelenses deram o primeiro passo rumo aos chips infinitamente pequenos, da ordem de grandeza do nanômetro, a bilionésima parte do metro.(...) construíram um fio de prata "automontável" de 12 mil nanômetros de extensão, capaz de conduzir eletricidade. Para unir as partículas que formam o fio cerca de mil vez mais fino que um fio de cabelo, os cientistas usaram moléculas de DNA, o material genético das células. Esse é o primeiro componente nanoeletrônico montado dessa forma que funciona. (Folha de São Paulo 03 de maio de 1998, grifos nossos)

Ainda marcada pelas possibilidades, uma reportagem apresenta a criação de uma nanobalança e aponta as potencialidades desse equipamento para a área médica.

Cientistas de institutos do Brasil e dos EUA criaram em laboratório a menor balança do mundo, capaz de medir a massa de objetos de bilionésimos de grama, como vírus. 'A balança poderia ser usada para determinar a massa de vírus individuais e, assim, estudar pequenas variações entre eles'" (Folha de São Paulo, 5 de março de 1999, grifos nossos) 


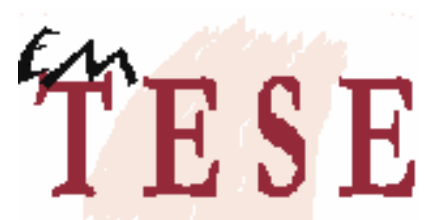

Revista Eletrônica dos Pós-Graduandos em Sociologia Política da UFSC

Vol. 4 n. 2 (2), janeiro-julho/2008

ISSN 1806-5023

Dos 61 artigos analisados, 7 versavam sobre os riscos potenciais da nanotecnologia, 49 apresentavam os possíveis benefícios, sobretudo na medicina e informática e 5 descreviam algumas descobertas, mas sem o posicionamento claro se a nanotecnologia traria benefícios ou prejuízos para a sociedade. É interessante ressaltarmos que mesmo não se tendo consenso sobre os efeitos da nanotecnologia, a ênfase dada é no otimismo de possíveis benefícios.

\section{Auto-replicantes e gosma cinzenta: ameaças na nano}

A primeira vez que a Folha de São Paulo noticiou a nanotecnologia como risco, foi no artigo intitulado "O lado ameaçador da tecnologia". Nele foi apontado o perigo da nanotecnologia 'cair em mãos erradas' ou dos cientistas perderem o controle, o que levaria a um cenário de máquinas auto-replicantes.

Bill Joy, cientista-chefe da Sun Microsystems, adverte que a espécie humana pode estar à beira do suicídio coletivo. (...) A nanotecnologia se refere a operações de engenharia mecânica realizadas em escala molecular. O Santo Graal dos nanotecnológicos é a química submicroscópica ou máquinas mecânicas chamadas montador, que são capazes de se reproduzir e reparar por conta própria. (Folha de São Paulo, 05 de abril de 2000)

O próximo texto em que é descrito algum tipo de risco, que poderia vir a ser oferecido pela nanotecnologia, foi de 30 de setembro de 2001, isto é, 14 meses depois.

“(...) podemos imaginar nanorrobôs que possam se auto-replicar em apenas um segundo. Passados 60 segundos, um exército de em torno de um bilhão de bilhões de nanorobôs teria sido criado. (...) E se algo desse errado e alguém construísse nanorrobôs malignos, capazes de nos atacar, como parasitas? Em uma visão bem negra, o planeta inteiro terminaria coberto por essas máquinas, como por um enxame de abelhas." (Folha de São Paulo, 30 de setembro de 2001, grifos nossos)

Depois da ameaça de nanorrobôs mal intencionados, a matéria segue afirmando que essa ameaça não seria real. $O$ próximo texto em que os riscos da nanotecnologia são evidenciados é de 23 de fevereiro de 2003. Nesse artigo o jornalista se mostra preocupado com o fato de haver pouco debate público sobre a nanotecnologia. Enfatizando que essa escassez de debate público contribui para o desconhecimento e, conseqüentemente reações extremistas de 


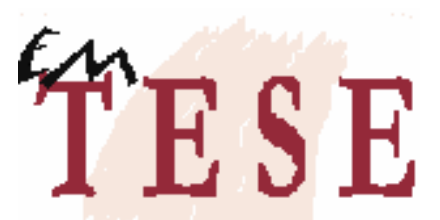

Revista Eletrônica dos Pós-Graduandos em Sociologia Política da UFSC

Vol. 4 n. 2 (2), janeiro-julho/2008

ISSN 1806-5023

defesa ou ataque. Essas reações extremadas podem levar a moratória das pesquisas ou a paralisação do debate público. De fato, no Brasil, no caso dos transgênicos, ou OGMs, o debate foi estéreo ${ }^{8}$.

Com razão ou sem ela, as pessoas aprenderam a temer tudo que a tecnociência produz de pequeno ou invisível e que tem potencial para causar dano a seres humanos e ao ambiente. (...) Não há motivo para que não seja assim com a nanotecnologia (...). organização nãogovernamental ETC (...) lançou na Cúpula de Johannesburgo, em setembro de 2002, a idéia de uma moratória para pesquisas nanotecnológicas.(...) [A ECT acredita na] ameaça de dispositivos nanoscópicos capazes de produzir cópias de si mesmos, que poderiam um dia cobrir o planeta e torná-lo inabitável. É o fantasma da "gray goo" (meleca cinza) que assombrou Bill Joy num já famoso artigo para a revista "Wired", em 2000. Aqueles que não confiam em ONGs devem então atentar para o que diz Richard Smalley, Nobel de Química de 1996. Num depoimento ao Congresso dos EUA em 1999, Smalley disse que "o impacto da nanotecnologia na saúde, na riqueza e no padrão de vida das pessoas será no mínimo equivalente às influências combinadas da microeletrônica, do diagnóstico por imagens, da engenharia computadorizada e dos polímeros artificiais neste século. (Folha de São Paulo 23 de fevereiro de 2003)

O próximo artigo que apresenta uma visão de alguns dos críticos da nanotecnologia tem curioso título "A gosma de US\$ 3,7 bilhões" e destaca, inicialmente, os altos investimentos que vêem sendo realizados pelo governo norte-americano para depois apresentar algumas visões sobre possíveis ameaças.

A nanotecnologia, ou pesquisa com dispositivos na escala do milionésimo de milímetro (nanômetro), tem motivado algumas previsões aterrorizantes, como a de que nanorrobôs auto-replicantes viessem a cobrir a Terra com uma gosma cinza. Esse fantasma da

8 A esse respeito Guivant, 2006, p. 2 esclarece que: “(...) no Brasil, onde há uma desconsideração sobre a participação pública nos debates sobre transgênicos. Estes giram em torno de atores sociais organizados, que atuam sem representatividade ou sem procurar construí-la." 


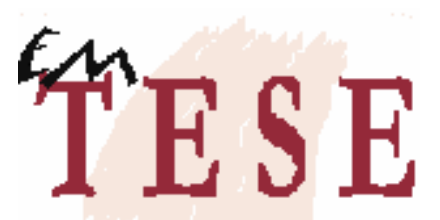

Revista Eletrônica dos Pós-Graduandos em Sociologia Política da UFSC

Vol. 4 n. 2 (2), janeiro-julho/2008

ISSN 1806-5023

"gray goo" foi aventado há alguns anos por Bill Joy, da empresa de computadores Sun. (...) Uma das conclusões, segundo a revista "The Scientist" (www.the-scientist.com), é que os mecanismos de supervisão e controle da pesquisa já existentes seriam suficientes para dar a devida expressão a preocupações de ordem ética e ambiental, como invasão da privacidade por nanodispositivos e danos à saúde respiratória por nanotubos de carbono.(...) Já Roger Kasperson, especialista em risco do Stockholm Environment Institute e da Clark University, disse que a nanotecnologia tem potencial enorme tanto para riscos quanto para benefícios. (Folha de São Paulo, 4 de janeiro de 2004, grifos nossos)

Já em outro artigo, muito mais comedido, são apresentadas as precauções do governo inglês para evitar o extremismo contra ou a favor da nanotecnologia. Pois como já afirmamos acima, essas posições já desencadearam a paralisação de debates no caso dos alimentos geneticamente modificados:

(...) os britânicos decidiram atuar preventivamente no caso das nanotecnologias -que lidam com objetos na escala do nanômetro (...) A primeira consideração geral do estudo vai na linha do comedimento: partículas dessa dimensão, a mesma de átomos e moléculas, têm tudo para ser quimicamente muito mais reativas do que outras da mesma substância em escala maior. Isso porque elas têm uma superfície proporcionalmente maior, portanto uma quantidade maior de átomos e moléculas exposta para interação com outras partículas (...) O relatório também exorciza sumariamente o mais popular dos nanofantasmas, o da "gosma cinza" -temor de que nanorrobôs autoreplicantes cubram a superfície da Terra, sufocando todas as formas de vida. (Folha de São Paulo, 29 de agosto de 2004)

É perceptível que em todas as críticas sobre os possíveis efeitos nefastos da nanotecnologia usa-se a metáfora da gosma cinzenta 'gray goo'. O uso de metáforas para na construção de problemas ambientais já foi brilhantemente discutido por Hannigan (1995, p.63)

(...) a extrema redução da camada de ozono tornou-se muito mais vendável como um problema ambiental quando representado como 


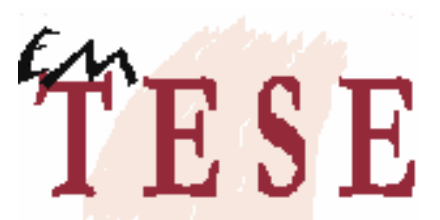

Revista Eletrônica dos Pós-Graduandos em Sociologia Política da UFSC

Vol. 4 n. 2 (2), janeiro-julho/2008

ISSN 1806-5023

um buraco que se expande.(...) De forma semelhante, os efeitos da chuva ácida foram dramatizados com êxito quando os ambientalistas alemães começaram a utilizar o termo Waldsterben (morte das folhas da floresta).

Pensar em efeitos prejudiciais da nanotecnologia de modo abstrato poderia ter uma força de comoção pública limitada. Mas imaginar que a terra será inundada por uma gosma cinza formada por nanorrobôs auto-replicantes, a força é muito maior. Ou utilizando as categorias de Bruno Latour, a goma cinza é um aliado ${ }^{9}$ não humano que fortaleceu a rede dos que acreditam nos efeitos nocivos da nanotecnologia e a entendem como um perigo à população mundial. Recorrendo as categorias desenvolvidas por Hannigan, podemos afirmar que goma cinza é mais "vendável" como um problema ambiental.

\section{De micro robôs a escala de medida: as diferentes explicações sobre o que é nanotecnologia}

Buscaremos analisar se ao longo desses quase dez anos em que a temática da Nanotecnologia vem sendo abordada no jornal Folha de São Paulo, houve ou não mudança na forma como a nanotecnologia é explicada pelos jornalistas. Verificamos que na primeira notícia sobre nanotecnologia, o uso de "robôs microscópicos" e "pequenos robôs" eram feitos para explicar o que é nanotecnologia, também se escrevia sobre manipulação de átomos, conforme observaremos na notícia abaixo:

Uma nova tecnologia está prestes a deixar ultrapassado tudo o que já se ouviu falar sobre miniaturização. Estamos falando da nanotecnologia. Os pesquisadores dessa nova área pretendem desenvolver, por exemplo, robôs microscópicos, capazes de penetrar no corpo humano para combater agentes infecciosos e reparar artérias danificadas. As pessoas poderão viver por mais tempo se esses equipamentos, milhares de vezes menores que a espessura de um fio de cabelo, forem capazes de reparar qualquer parte do organismo, deixando-o em perfeito estado.(...) Mas isso deverá ser

9 Bruno Latour acredita que para que determinada descoberta científica seja considerada verdadeira, o cientista precisa mobilizar diversos atores em sua rede sociotécnica. O cientista terá maior exito quanto maior for seu poder de convencimento. Tal poder se dará pela força do aliados, que podem ser humanos e não humanos que foram mobilizados, e não pelas qualidade intrínsecas da teoria científica. (Latour, 2005) 


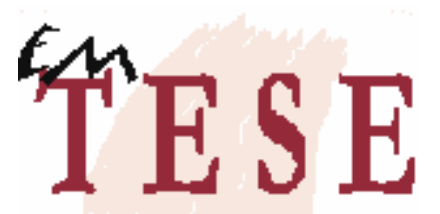

Revista Eletrônica dos Pós-Graduandos em Sociologia Política da UFSC

Vol. 4 n. 2 (2), janeiro-julho/2008

ISSN 1806-5023

apenas o início, pois as possibilidades da nanotecnologia são infinitas

e seus avanços deverão ser enormes em todas as áreas do conhecimento(...) A idéia central de Drexler é montar, a partir da manipulação de átomos e moléculas, pequenos robôs que seriam capazes de se replicar construindo outros. Esses nanorrobôs, e toda a nanomaquinaria por eles construída átomo por átomo, seriam capazes de fabricar desde um pedaço de carne a uma nave espacial. Tomandose por base que toda a matéria é constituída por átomos, qualquer substância serviria de matéria-prima, inclusive, lixo. (...) (Folha de São Paulo, 19 de outubro de 97, grifos nossos)

Em outro artigo a nanotecnologia é associada a produção de equipamentos:

(...) São muitas as promessas da nanotecnologia, que trata do desenvolvimento de equipamentos em escala de nanômetros bilionésimos de metro.(...) (Folha de São Paulo, 2 de agosto de 1998, grifos nossos).

Essa mesma explicação é repetida em outro artigo no ano seguinte. Seguem-se então várias matérias em que não é apresentada, aos leitores, uma explicação sobre o que significa nanotecnologia.

Somente em 2003, retornam as explicações, e nesse caso já com mudanças significativas em relação aos textos anteriores. Primeiramente desaparece o termo nanorrobôs e também reforça-se o entendimento de nanotecnologia como uma nova escala de medida:

(...) o Ministério da Ciência e Tecnologia (MCT) se mobiliza para tentar definir metas para a emergente área de nanotecnologia (criação de materiais, processos e equipamentos na escala dos milionésimos de milímetro) (Folha de São Paulo, 29 de abril de 2003, grifos nossos)

A mesma estrutura de explicação encontramos em outras matéria, como por exemplo:

A nanotecnologia envolve manipulação e uso de processos e sistemas na escala nanométrica (medida em milionésimos de milímetro). É nessas dimensões que os átomos e as moléculas costumam interagir. (Folha de São Paulo, 6 de junho de 2003, grifos nossos) 


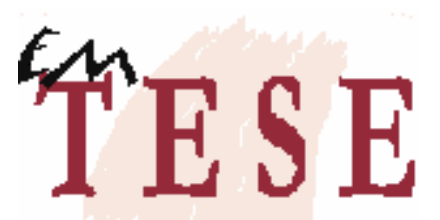

Revista Eletrônica dos Pós-Graduandos em Sociologia Política da UFSC

Vol. 4 n. 2 (2), janeiro-julho/2008

ISSN 1806-5023

Nos próximos textos a nanotecnologia é apresentada apenas como uma escala de medida, o artigo abaixo é ilustrativo nesse sentido:

As áreas de química e de produtos farmacêuticos são as que mais potencial têm hoje no Brasil para o desenvolvimento de nanotecnologias -produtos medidos em milionésimos de milímetro. (Folha de São Paulo, 22 de maio de 2005)

Mas para nossa surpresa a relação da nanotecnologia com máquinas, voltou a aparecer, mas o termo não foi o de nanorrobôs.

Essas são algumas da invenções da nanotecnologia, a ciência que estuda o comportamento de máquinas submicroscópicas. (Folha de São Paulo, 14 de agosto de 2005)

Mesmo tendo sido relacionada com máquinas no ano de 2005, é perceptível que houve uma mudança na forma como a nanotecnologia é explicada ao público. Certamente, parece ter havido uma preocupação em desvincular a nanotecnologia da 'gosma cinza', a utilização do termo nanorrobô foi diminuindo no decorrer dos anos. Depois que a metáfora gosma cinza foi apresentada como possível conseqüência nefasta da nanotecnologia, apenas em um artigo posterior voltou-se falar em nanorrobôs como promotores de benefícios. Possivelmente essa mudança na terminologia é reflexo da confrontação que os cientistas tiveram com movimentos sociais que se colocaram contra o desenvolvimento de pesquisas na área de nanotecnologia. Hannigan, no explica que quando um confronto passa a ocorrer, os cientistas precisam modificar a forma como apresentam a nova tecnologia. Uma das estratégias é criar novas metáforas positivas e construir novas imagens que reforcem os efeitos benéficos da tecnologia em desenvolvimento.

Nessa situação, os cientistas são forçados a reunir e promover o seu próprio conjunto de exigências interpretativas, quer para justificar porque razão um problema existe e a sua investigação deveria continuar, ou porque é que a sua investigação não deveria ser interpretada como constituindo um problema. (Hannigan, 1995, p. 106)

Esse situação citada pelo autor, foi verificada em uma das matérias. Nela utiliza-se a proteção a saúde de crianças para construção de imagem positiva. Nessa matéria, apresentou-se as potencialidades da nanotecnologia para a indústria têxtil, é foi entrevistado um pesquisador 


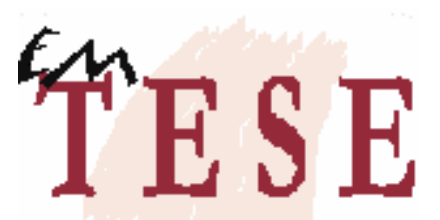

Revista Eletrônica dos Pós-Graduandos em Sociologia Política da UFSC

Vol. 4 n. 2 (2), janeiro-julho/2008

ISSN 1806-5023

que está trabalhando no desenvolvimento de tecidos que liberem substâncias antibacterianas ou fungicidas. O próprio pesquisador destaca: "Você não teria de se preocupar muito se uma criança usando uma roupa como essa fosse brincar num lugar sujo”. (Folha de São Paulo, 2 de agosto de 2005).

\section{Conclusão}

Em nossa análise de conteúdo sobre nanotecnologia no jornal Folha de São Paulo, percebemos que na maior parte dos artigos jornalísticos os possíveis efeitos positivos da nanotecnologia são evidenciados. Também é interessante ressaltar que nos primeiros artigos a nanotecnologia era representada como uma tecnologia "revolucionária" e que promoveria grandes mudanças em nosso cotidiano, sobretudo na área médica; mas esse tipo de abordagem perdeu espaço. No decorrer do tempo, efeitos menos grandiosos e mais pontuais começaram a ser apontados. O caso da indústria têxtil é ilustrativo. Em uma reportagem se apresentou as inovações no desenvolvimento de tecidos "que não desbotam nem com reza braba" ou o nanocooton "[que] possibilitaria lençóis melhores e mais confortáveis", ou ainda tecidos que "ajudariam a ficarmos protegidos de germes e bactérias". É possível que essa mudança tenha se dado em função de que pesquisas em áreas específicas, começaram a apresentar resultados concretos, que foram sendo trazidos para conhecimento público. Assim, o leitor que desde 1997 esperava os efeitos "revolucionários" da nanotecnologia não fica tão desapontado. No momento não se convive com nanorrobôs desobstruindo as artérias coronarianas; mas ao menos é possível levarmos para casa lençóis mais macios!

Não podemos afirmar que a nanotecnologia é entendida, por parte significativa da população brasileira como um problema ambiental. O único consenso, entre pesquisadores, é que há um desconhecimento público generalizados sobre a temática. Não temos conhecimento de pesquisas significativas sobre a percepção dos riscos e benefícios da nanotecnologia entre os brasileiros. Mas em nossa análise ficou bastante claro que o uso da metáfora da gosma cinza para explicitar as preocupações com os possíveis riscos da nanotecnologia é recorrente, e de certa forma, bastante eficaz na promoção de uma problemática ambiental. Já que o uso de tal metáfora parece ter promovido mudanças na maneira como a nanotecnologia passou a ser explicada ao público. Ou seja, se na década de 90 e a nanotecnologia era associada a nanorrobôs, nos últimos a nanotecnologia passou a ser apresentada como uma escala de medida. 


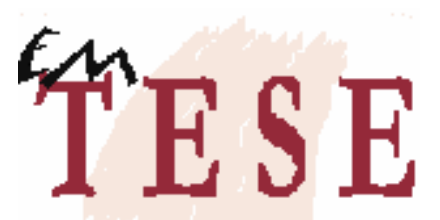

Revista Eletrônica dos Pós-Graduandos em Sociologia Política da UFSC

Vol. 4 n. 2 (2), janeiro-julho/2008

ISSN 1806-5023

Acreditamos que a percepção pública da nanotecnologia como um problema ambiental ainda não foi construída no Brasil, talvez não venha a sê-la, isso dependerá de como serão articulados as negociações entre diversos atores, humanos e não humanos.

\section{Referências}

BACHELARD, G. Filosofia do novo espírito científico: a filosofia do não. Lisboa: Presença. 1974

BACHELARD, G. A epistemologia não cartesiana. IN: Os pensadores. SP: Abril, 1988.

BAUER, M. W. Análise de conteúdo clássica: uma revisão. IN: GASKELL e BAUER (orgs). Pesquisa qualitativa com texto, imagem e som. RJ: Vozes.2004

BARDIN, Laurence. Análise de conteúdo. Lisboa: Edições 70, 1979.

CARDOSO, Miriam Limoeiro. Ideologia do Desenvolvimento - Brasil: JK -JQ. Rio de Janeiro, Paz e Terra, $2^{\text {a }}$ ed. 1978.

CIÊNCIA HOJE. Rio de Janeiro: Sociedade Brasileira para o Progresso da Ciência, n. 1, julho/agosto 1982.

CHIZZOTTI, Antônio. Pesquisa em ciências humanas e sociais. Rio de Janeiro: Cortez, 1991.

GUIVANT, J. S. Transgênicos e percepção pública da ciência no Brasil. Ambiente \& sociedade. Campinas, Unicamp: , v. IX, n.1, 2006.

HANNIGAN, John. Sociologia ambiental. A formação de uma perspectiva social. Lisboa: Instituto Piaget. 1995.

LATOUR, B. Reassembling the social. An introduction to Actor-Network-Theory. Oxford: Oxford University press. 2005

PEREIRA, Luiza Helena. Análise de conteúdo: um aprroachdo social. Cadernos de Sociologia, Porto Alegre, v.9, p.87-114, 1998.

SOTO, William H. A análise do discurso nas ciências sociais. Cadernos de Sociologia. Porto Alegre, vol. 9, p. 161/187, 1988. 